\section{Definition of a collaborative working model to the logistics area using design for Six Sigma}

Definition of a collaborative working model

\author{
Maria Sameiro Carvalho, Dora sousa Magalhaes and \\ Maria Leonilde Varela \\ Department of Systems and Production, University of Minho, \\ Braga, Portugal \\ Jorge Oliveira Sa \\ Department of Information Systems, University of Minho, \\ Guimarães, Portugal, and \\ Isabel Gonçalves
}

Department of Logistics, Bosch Car Multimedia, Braga, Portugal

\begin{abstract}
Purpose - The purpose of this paper is to create an online enterprise community for all logistics employees of Bosch Car Multimedia division in the Bosch Group, for an internal collaboration of the entire Bosch Group based on an IBM Connections platform: Bosch Connect. An additional concern, collected throughout the project, was to bring employees to join the platform, making it a tool of your daily work. The final objective is to implement and promote a tool to foster internal and external integration of the Bosch logistics community.

Design/methodology/approach - A case study is presented to illustrate the use of a Design for Six Sigma (DFSS) methodology to support all the process creation of a collaborative community. There are several variants of the methodology DFSS. For the context of this project, will be used the define, measure, analyze, design and verify (DMADV) methodology, that is appropriated to design services processes and it addresses specifically to the remodeling processes.

Findings - The use of DMADV methodology allows establish, systematically, a model which was in accordance with the target population needs.

Research limitations/implications - Since this is a case study, it is not possible to generalize the results. Furthermore, this project was developed in a limit time (about four months). Thus, was not possible to obtain a large community.

Practical implications - The case study brings some evidence of how a systematic approach to the design of a online enterprise community can support designers to meet user's needs.

Social implications - A new approach is proposed to meet an online enterprise community user's needs.

Originality/value - To the best of the authors' knowledge, there is no evidence the use of this methodology to support a construction of an online enterprise community.
\end{abstract}

Keywords Enterprise 2.0, Design for Six Sigma, Web 2.0, Collaborative tools,

Online enterprise community

Paper type Case study

\section{Introduction}

In today's global economy, collaboration has become an essential requirement for an effective functioning society. The emergence of Web 2.0 has been announced as a set of tools to facilitate collaboration (Chu and Kennedy, 2011). The use of Web 2.0 technologies power the internet in a more interactive and collaborative way, increasing the social interactions of individuals and their commitment (Murugesan, 2007).
Received 26 November 2014
Revised 16 June 2015
29 September 2015
Accepted 7 December 2015

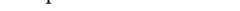


IJQRM

33,4

466

The collaboration can simplify and become more effective the development of processes, relatively to time and quality, exploring knowledge of specific people in these processes, inside the organization (Bianchini et al., 2012).

The Bosch Group is a clear example of globalization, where their entire organization crosses more than 150 countries. In all the supply chain (even inside the organization) there is a need to communicate and collaboration between these associates that are distributed worldwide.

Since 1886, that Bosch innovates and remains competitive. Up today, the communication has been performed around a network of documents, through static HTML pages and with low dynamic contents (Web 1.0). Bosch wants to overcome this state and achieve a communication across the social web, i.e., through social interactive tools on the internet (Web 2.0). It is in this context that appears the Enterprise 2.0 project that aims to become Bosch in a high-connected enterprise, where the slogan is "Cooperate. Communicate. Create" (Bosch, 2013). This project crosses all the supply chain with the purpose to integrate all the stakeholders. Based and adapted from IBM Connection to Bosch Group, Bosch Connect is the internal platform of Enterprise 2.0 project. This platform offers a diversity of functionalities to increase efficiency of communication and collaboration among associates. It is in the context of using this type of collaborative platforms that this project emerges, exploring Bosch Connect in the logistics section of Car Multimedia division.

To support the project development, the Design for Six Sigma (DFSS) methodology was selected in order to minimize the occurrence of unforeseen events that are traditionally associated with the introduction of new products, services and processes (Hahn et al., 2000). For the context of this project, the DMADV roadmap will be used since it is appropriated to design services processes and it addresses specifically to the remodeling processes.

\section{Literature review}

\subsection{Collaboration in the companies}

In the twenty-first century, an economy that is based on knowledge has been emerging, the information and communication of knowledge are crucial to the organization's success (Wijaya et al., 2011). The modern organizations support and promote internal collaboration to improve the performance of their own processes (Bianchini et al., 2012).

\subsection{Web 2.0}

Globalization keeps on going up, meaning that nowadays more organizations need to be able to operate in more complex environments (Don and Anthony, 2006). The importance of the business communities, confirm that there is a change in the business models from a traditional and competitive hierarchical system, to a more collaborative environment and social network, that are considered two of the most import concepts of Web 2.0 (Lytras and García, 2008). The Web 2.0 technologies made some significant improvements, providing the users with the necessary tools to adopt and promote a collaboration culture in the corporations (Fuchs-Kittowski et al., 2009). The Web 2.0 is defined as the "the philosophy of maximize the collective intelligence and additional values to each user, by sharing formal and dynamic information" (Hoegg et al., 2006).

Wikis, blogs, podcasts, folksonomies (tags), mashups, social network, virtual words, crowdsourcing and Really Simple Syndication feed are Web 2.0 technologies that allow 
companies to grow, in a profitable way, their productivity and competitiveness (Andriole, 2010). Andriole (2010) split the advantages that users can gain from using Web 2.0, in six big groups: knowledge management, quick development of applications, relationship's management with the clients, collaboration and communication, innovation and formation. Currently, it is still not possible to measure the real impact of Web 2.0 in the business world (Andriole, 2010). Some technologies, such as wikis, blogs and social networks, have been developed more than other Web 2.0 technologies, probably because of the fear of the unknown (Eales-Reynolds

Definition of a collaborative working model et al., 2012). To assure all the advantages of these technologies, companies will have to increase their surveillance on internet and invest in preventive measures (Murugesan, 2007).

\subsection{Enterprise 2.0}

McAfee (2006a) created the term "Enterprise 2.0" to describe "the use of emerging social platforms in the companies, or between companies and their business partners or clients." Ramírez-Medina (2009) says that "Enterprise 2.0" is the application of Web 2.0 technologies in an industrial environment, in order to allow the collaborators to share ideas, communicate, cooperate and create new contents. In this context, a series of platforms have been created, like IBM Connections and Zimbra Community, to offer tools that allow companies to link them socially and support the opinions and feedbacks from the users and platforms to manage contents form the users. Enterprise 2.0 offers to innovative organizations the opportunity to use the creativity of their collaborators and to increase the productivity and aggregate additional value to their daily work (Bin Husin and Swatman, 2010). Rangaswami (2006) refers that Enterprise 2.0 is more a combination of Web 2.0 tools, with a lighter software requirements and friendly user.

To implement the Enterprise 2.0, interactively and collaboratively, it's important that the company have proper technological and organizational conditions. The implementation process is a critical and complex procedure that requires a strategy plan to help the adoption of the new tool (Consoli, 2013). Regardless the companies investment in more Enterprise 2.0 collaborative tools to support and share knowledge, to enhance communication and collaboration, most of them face a difficult challenge, the adoption of the tools by the collaborators (Louw and Mtsweni, 2013). Despite these interactive tools, not all collaborators are predisposed to adopt Enterprise 2.0 (Bin Husin and Swatman, 2010). This factor or resistance by the target audience tend to appear when a new technology emerges. The resistance is known as the "Empty Quarter" (McAfee, 2006b), that is the group of users that decline the new technology. This could happen when there is a low technology interest, a repeated use of some technologies, a low corporative culture and a non-friendly and complex technology to learn. To sum up, McAfee (2006b) believes that is essential that those collaborators should be aware of the benefits of Enterprise 2.0, taking in consideration that it's a tool that will provide larger and better access to knowledge and experiences to the company.

\subsection{DFSS methodology}

The Design for Six Sigma (DFSS) methodology emerges from the need to adapt the Six Sigma to the design projects, having as goal to design products, services and processes in the light of the Six Sigma (Chowdhury, 2002). It is a process to define, design and 
IJQRM

33,4

468

deliver innovative products that provide competitively attractive value to customers in a manner that achieves the critical-to-quality characteristics for all the significant functions (Watson and Deyong, 2010).

DFSS complements the Six Sigma improvement methodology but takes it one step further ferreting out the flaws of the product and the process during the design stage (not the quality control stage or even the production stage) (Chowdhury, 2002). One of its main goals is to minimize the occurrence of unforeseen events that are traditionally associated with the introduction of new products, services and processes (Hahn et al., 2000).

While Six Sigma focusses on improving existing designs, DFSS concentrates its efforts on creating new and better ones (Chowdhury, 2002). DFSS requires applying resources to finding out what customers really want, and then devoting the entire project to meeting the needs and desires of these customers. This works whether the customer is external or internal, such as an associate or a department (Chowdhury, 2002). The DFSS approach seeks inventive ways of satisfying and exceeding customer requirements and expectations (Shahin, 2008).

For De Mast et al. (2011), what define DFSS is the more emphasis manufacturability, reliability, maintainability, instead of ideal performance. The authors highlight the following principles relating to DFSS:

- Robust design (design products and processes in such a way that they function well in non-ideal circumstances).

- Reduce complexity of products and processes (thus reducing the probability of mistakes).

- Inventory as early as the design phase which mistakes and problems are likely to occur; and design preventive mechanisms.

- Altogether the emphasis is on robustness and mistake-proneness and less on ideal performance.

- The driving principle is not technology but added value for stakeholders. Good product and process design is not exclusively technology driven but is also driven by what stakeholders consider to be value. In DFSS this is embodied by a disciplined translation process that starts from the stakeholder. Its functional requirements are translated to technical requirements and these are translated into product specifications and process settings and finally a control plan. Critical parameter management is applied to keep track of the relationships of parameters on different levels.

- Emphasis on the early warnings, including testing and feedback in the early stages of the design process to ensure that the designers focus on weaknesses in the design, instead of being carried away by a drive to continue improving features that are already strong points.

According to Shahin (2008), organizations have adopted a variety of approaches that have resulted in acronyms, as follows:

- DMADV: define, measure, analyze, design, verify;

- IDOV: identify, design, optimize, validate;

- DIDES: define, initiate, design, execute, sustain; 
- IIDOV: invent, innovate, develop, optimize, verify;

Definition of a

- CDOV: concept development, design development, optimization, verify, certification;

- DCOV: define, characterize, optimize, verify; and collaborative working model

- IDEAS: identify, design, evaluate, assure, scale-up.

Despite these naming differences, all versions of DFSS share fundamental strategies 469 and tools that promote a common goal: to create a data-driven product development culture that efficiently produces winning products (Shahin, 2008).

There are several case studies in the literature illustrating the adoption of DFSS methodology in order to develop products or systems, for example, in Johnson et al. (2006). However, to the best of our knowledge, this roadmap has not been used to follow a development of an online enterprise community.

\section{Problem description}

In August 2012, Bosch Connect was officially released in Bosch Group with a pilot project at the Diesel Systems division. A survey, conducted in February 2013, revealed that at least 36 percent of users have contributed to some topic in Bosch Connect and about 77 percent use the tool during 20 percent of their daily work (Bosch, 2013). In September 2013, Bosch Connect became available to all associates through the internal intranet portal. In January 2, 2014, approximately 80 percent of all the associates were registered in Bosch Connect. However, only 33 percent of those were active users (Bosch, 2013). Given the presented data, there was the need to develop a project that aimed to promote communication and collaboration among the logistic associates in Car Multimedia division, by building a community in Bosch Connect.

\section{Proposed approach}

To support all the creation process of the community, the Design for Six Sigma (DFSS) methodology was selected. One of its main goals is to minimize the occurrence of unforeseen events that are traditionally associated with the introduction of new products, services and processes (Hahn et al., 2000). From the several variants of the DFSS methodology the DMADV roadmap was used in the context of this project because it is appropriated to design resource efficient services and processes which are highly linked to customer demands (Shahin, 2008) and it addresses specifically the processes of remodeling (Yang, 2005). DMADV is one way to summarize how DFSS fits into an overall business system (Watson and Deyong, 2010). Also. This variant of DFSS involves the following steps:

(1) Define: the first phase consists in the identification of the product, service or process to be constructed (or reconstructed); including the scope identification, goals, resources and construction of the project plan (Hahn et al., 2000).

(2) Measure: the second phase of the DMADV methodology aims to drive the necessary actions to collected every customer's need or requirement and translate them into measurable characteristics (Hahn et al., 2000). Thus, it will be possible to identify all critical to quality characteristics (CTQs) (Johnson et al., 2006). 
IJQRM

33,4

470

(3) Analyze: in this step it is analyzed all the collected data on the previous phase (measure). Alternative designs should be generated and assessed and an action plan to fulfill all the CTQs should be elaborated (Hahn et al., 2000).

(4) Design: based on the design variables and parameters the detail of the entire project structure is defined, converting the CTQs into critical elements of the process It is also need to evaluate the project's capacity and develop a verification plan (pilot test) (Hahn et al., 2000). It is one of the most critical steps since it can determine the success of the all project.

(5) Verify: this step consists in the verification and evaluation of the product developed in the project. Furthermore, this phase includes the development of any additional action referred in that same validation (Hahn et al., 2000).

\section{Project development}

In the next subsections, each phase of the DMADV roadmap that was developed under this project will be presented.

\subsection{Define phase}

The aim of this project was to construct an online community to all the logistics associates in Car Multimedia division. The main resource of the project was the Bosch Connect platform. To achieve the target, the project plan was defined, according to DMADV methodology steps: first, define phase: current phase where the project is initiated and planned; second, measure phase: identify the target population, interviews to logistic leaders and surveys to the target population; third, analyze phase: define critical characteristics to the community; fourth, design phase: construct the community structure; and finally, verify phase: collect feedback, implement improvement actions and presentation of future work proposals.

\subsection{Measure phase}

The target population of this project was the logistics associates in four geographically dispersed plants: Braga (Portugal), Hildesheim (Germany), Penang (Malaysia) and Wuhu (China), in a total of 146 persons. Through interviews and a survey, it was possible to collect all target population needs. With the survey results, it was verified that the adherence level to Bosch Connect was, at that moment, short. Many users did not access regularly the platform, or simply did not use it (about 45 percent of the responders). The respondents that already used Bosch Connect regularly, could give an important view of the platform, because they already knew it. On the other hand, if they did not enjoy the platform, they could negatively influence other users and did not accept new perspectives. Anyway, for all users it was really necessary to show them the benefits and potentials associated with the use of Bosch Connect.

\subsection{Analyze phase}

According to the information collected in the interviews and surveys, it was possible to conclude that the target population's needs match. In Table I, all those needs were identified, and the "X" on the columns "Interview" and "Survey" reveals where they was requested.

The choice of each application was based on an official document of the company. This document consists in a flowchart. According to the type of information to share, it 
defines the best application to use in Bosch Connect. For example, in "Share the Car Multimedia logistics news" the author goal is to share information, in a single broadcast information share, the best application will be the blog.

\subsection{Design phase}

The name selected to the logistics Car Multimedia community was "Be One Logistics." To define this community, all the applications mentioned in Table I were used, in order to achieve all the respondent's needs. In Figure 1, an overview of this community is presented.

During the community construction, the concern to keep the information attractive, clear, easy to read and to access was present. So, the main goal of the overview page was to show, by topics, all the content present in the community with these guidelines. According to this concern, in the community overview, an additional page (wiki page) as link was created, in order to provide additional information about the community and the involved project.

\subsection{Verify phase}

The last phase of the DMADV methodology is concerned with the verification and validation of the developed product (Hahn et al., 2000). In a qualitative level, several feedbacks were received and analyzed. Through those information, it was concluded that the target population understood the importance of having a training phase concerning the use of Bosch Connect platform, in order to become more effective and efficient its use; also the associates need to understand that their leaders appreciate and encourage the use of the platform. Additionally, it highlighted the importance of creating and keeping proximity with the community members, being constantly available for any clarification. In a quantitative level and among all collected indicators, the most important were those that were related to participation in the "Be One Logistics" community. Concerning the number of members, 103 persons represent about 90 percent of respondents and 71 percent of the target population. However, it was verified that the number of users (active members) was considerably low (41.7 percent).

By analyzing Figure 2, it was concluded that the community experienced 281 visits, in a month (accounting for all visitors, including anonymous users and repeat visitors). As for exclusive authenticated visitors, i.e., those who had logged in the community at least once, in each month, were at most 111 users. Both peaks of visits took place in

\begin{tabular}{lccl}
\hline & \multicolumn{2}{c}{ Required in } & \\
Themes to explore in the community & Interview & Survey & Application to use in Bosch Connect \\
\hline Information technology & $X$ & & Wiki \\
Plant and central projects & $X$ & & Wiki \\
WILCO Project & $X$ & & Subcommunity \\
LSC-CM meetings & $X$ & & Subcommunity \\
Discussion about Bosch Connect potential & $X$ & & Forum \\
Share the car multimedia logistics news & $X$ & $X$ & Blog \\
Share best-practices & $X$ & $X$ & Ideation blog \\
Logistics area's information & & $X$ & Wiki \\
Work instructions & & $X$ & Wiki
\end{tabular}

Definition of a collaborative working model

\section{$-$}


IJQRM

33,4

472

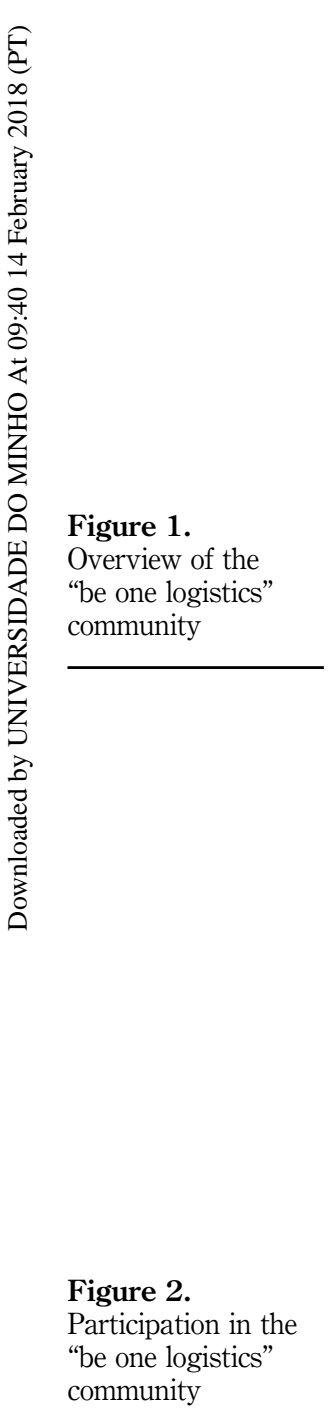

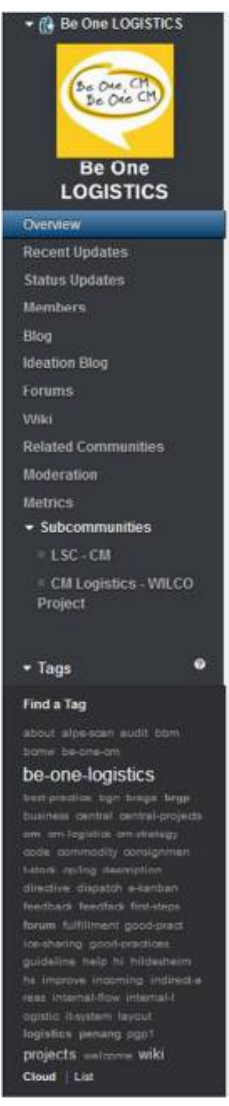

CM LEGISTICS

*:

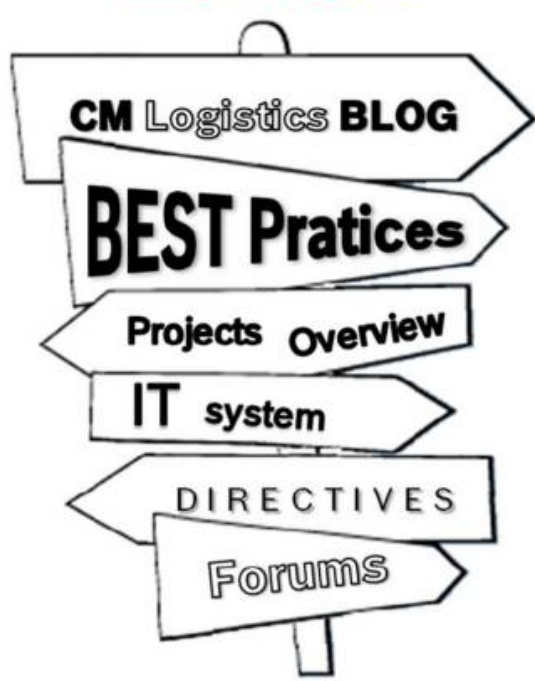

About Be One Logistics

Do you have any question? Plesst contact our community manager: Dora Magathäes

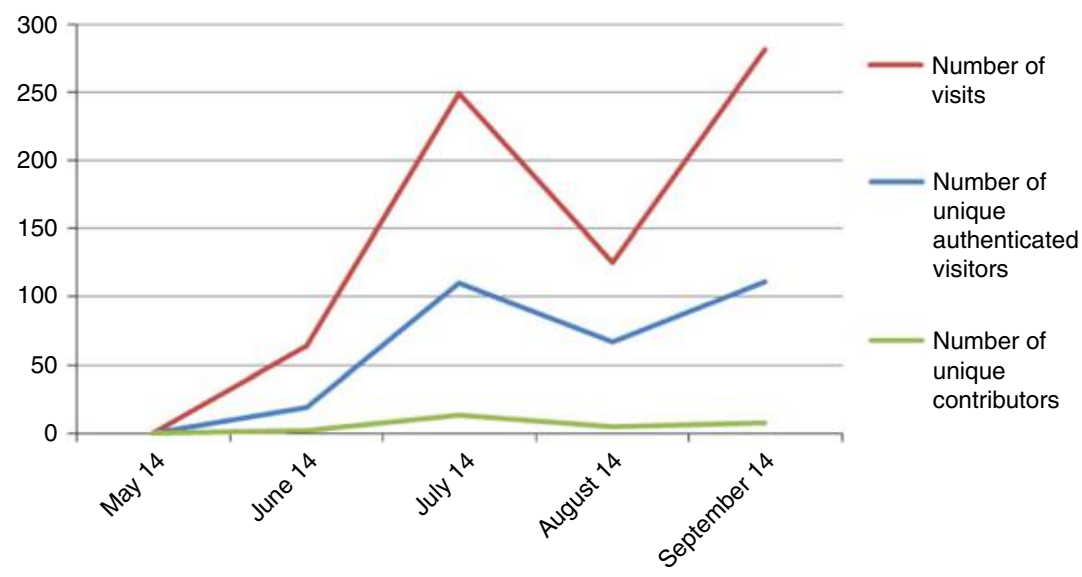


September and the biggest drop in August, where the value was justified by the period of vacations in all plants. In short, it is possible to verify that the number of accesses to the community progressively evolved. About the access to each application, it was verified that there is a balance among all of them, highlighting only the wiki (31 percent) and the blog (30 percent).

Concerning the number of new updates (Figure 3), a total of 617 participations were obtained, being its peak in June with 357 contributions. Regarding the applications where this content was created, Figure 4, is clearly verified that the element that Definition of a collaborative working model obtained the highest content creation and update was wiki (77 percent), possibly due to the nature of application that, in each page edition count one update. With regard to future proposals, it is highlighted the exploration of logistics area's information, keep the projects status updated and the trainings to Bosch Connect platform. In short, all future work will be directed according to the community member's needs, and will be received via their feedback.

\section{Results and discussions}

Through the creation of the "Be One Logistics" community in Bosch Connect, it was possible to achieve the goal of this project that was to improve communication and collaboration among logistics associates of Car Multimedia division. As final results, membership fee grew to 90 percent of respondents, 71 percent of the target population. Additionally, contributions in terms of content updates also grew, despite the relatively

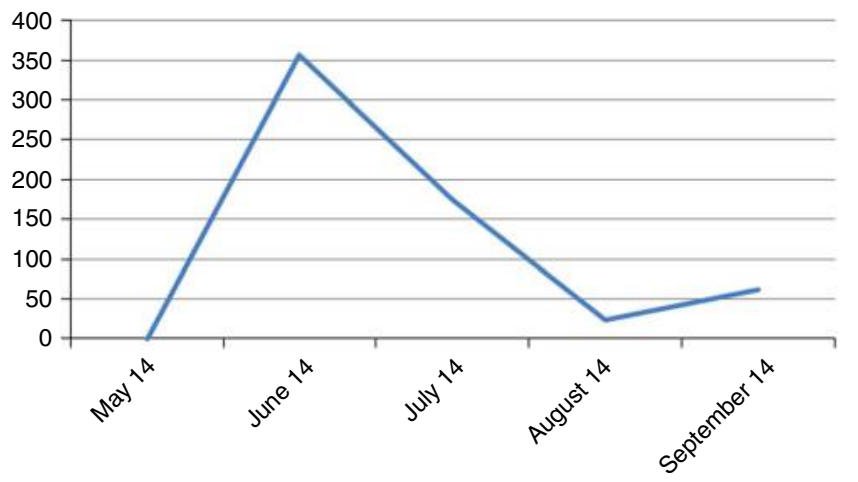

Figure 3.

Number of total content update, per month

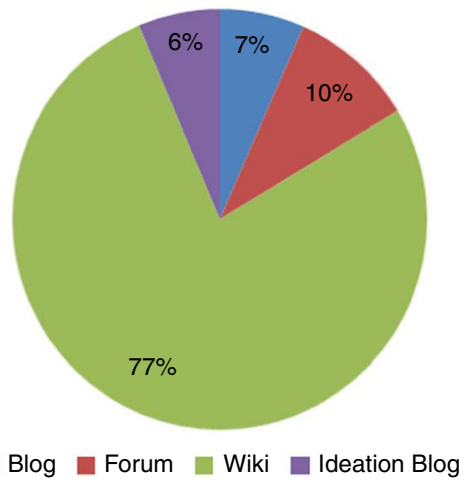

Figure 4.

Number of total content update, per application 
IJQRM

33,4

low number of users (41.7 percent, i.e. 43 of 103 members). Regarding the access, there was a balance between the use of various applications. On the other hand, a higher content update in the wiki was verified, with 77 percent of the total generated content. Finally, and not considering the vacation period (August) as significant, it was concluded that participation in the "Be One Logistics' community evolves gradually, in four months of use.

In this project, was identified some aspects that are considered limitations and influenced the development of this project. The first aspect was related to the fact that the target population was distributed by four distant countries. Related to the limited time of the project development is associated with the lack of opportunity to obtain a larger community, given that, through the feedbacks received, the community will always evolve to follow the needs of its members. Furthermore, and as mentioned Louw and Mtsweni (2013) about the implementation of the Enterprise 2.0, it was verified that the frequent use of Bosch Connect is also a lengthy adoption process. Finally, being aware of the "Empty Quarter" by McAfee (2006b), some resistance by some part of the target population in the use of this technology was observed, either during the investigation or in the various training stages, which has been shown to be quite negative because these people can influence their colleagues, negatively affecting the project.

\section{Conclusion}

To develop the purposed project, the DMADV methodology was used, a specific DFSS variant. Due to time limitations, there was not used any specific tool in design phase. So, in a future platform re-design process, the use of design tools such Robust Design or TRIZ techniques should be explored in order to improve this phase.

In conclusion, an essential factor for the success of the project is the involvement of the associates. It is also possible to conclude that this project helped to bring all logistics associates of Car Multimedia division, particularly in terms of communication and collaboration. Finally, it can be concluded that this project has a wide margin of continuous evolution, since it must always be pursued by the target population needs.

\section{References}

Andriole, S.J. (2010), "Business impact of Web 2.0 technologies", Communications of the ACM, Vol. 53, pp. 67-79.

Bianchini, D., De Antonellis, V. and Melchiori, M. (2012), “Collaborative mashup development in Enterprise 2.0”, Proceedings of the Fifth Interop-Vlab. It Workshop on Complexity of Systems, Complexity of Short Papers for Seminar IM, Brescia.

Bin Husin, M.H. and Swatman, P.M. (2010), "Removing the barriers to Enterprise 2.0", IEEE International Symposium on Technology and Society (ISTAS). IEEE, pp. 275-283.

Bosch (2013), Basic Presentation “Enabling Enterprise 2.0”, Intern Publications, Hildesheim.

Chowdhury, S. (2002), Design for Six Sigma, Financial Times Prentice Hall.

Chu, S.K.-W. and Kennedy, D.M. (2011), "Using online collaborative tools for groups to coconstruct knowledge”, Online Information Review, Vol. 35, pp. 581-597.

Consoli, D. (2013), “A conceptual model to implement an interactive and collaborative enterprise 2.0”, Informatica Economica, Vol. 17, pp. 36-47.

De Mast, J., Diepstraten, G. and Does, R. (2011), "Quality quandaries: design for Six Sigma: method and application”, Quality Engineering, Vol. 23, pp. 204-211. 
Don, T. and Anthony, W. (2006), Wikinomics: How Mass Collaboration Changes Everything. Portfolio, Penguin Group, New York, NY.

Eales-Reynolds, L.J., Gillham, D., Grech, C., Clarke, C. and Cornell, J. (2012), “A study of the development of critical thinking skills using an innovative web 2.0 tool", Nurse Education Todav, Vol. 32, pp. 752-756.

Fuchs-Kittowski, F., Klassen, N., Faust, D. and Einhaus, J. (2009), “A comparative study on the use of Web 2.0 in enterprises", Proceedings 9th International Conference on Knowledge Management and Knowledge Technologies, Graz, pp. 372-378.

Definition of a collaborative working model

Hahn, G.J., Doganaksoy, N. and Hoerl, R. (2000), "The evolution of Six Sigma”, Quality Engineering, Vol. 12, pp. 317-326.

Hoegg, R., Martignoni, R., Meckel, M. and Stanoevska-Slabeva, K. (2006), "Overview of business models for Web 2.0 communities", Proceedings of GeNeMe, pp. 23-37.

Johnson, J.A., Gitlow, H., Widener, S. and Popovich, E. (2006), "Designing new housing at the University of Miami: a "six sigma" DMADV/DFSS case study", Quality Engineering, Vol. 18, pp. 299-323.

Louw, R. and Mtsweni, J. (2013), "The quest towards a winning enterprise 2.0 collaboration technology adoption strategy", International Iournal of Advanced Computer Science \& Aphlications, Vol. 4, pp. 34-39.

Lytras, M.D. and García, R. (2008), "Semantic web applications: a framework for industry and business exploitation - what is needed for the adoption of the semantic web from the market and industry", International Iournal of Knowledge and Learning, Vol. 4, pp. 93-108.

Mcafee, A. (2006a), "Enterprise 2.0: the dawn of emergent collaboration", MIT Sloan Management Review, Vol. 47, pp. 21-28.

Mcafee, A. (2006b), "Evangelizing in the empty quarter", The Business Impact of IT : Worldpress.

Murugesan, S. (2007), “Understanding Web 2.0”, IT Professional, Vol. 9, pp. 34-41.

Ramírez-Medina, J.A. (2009), "Enterprise 2.0 readiness index. Management of engineering \& technology”, PICMET 2009. Portland International Conference on, 2009. IEEE, pp. 2677-2684.

Rangaswami, M.R. (2006), “The birth of Enterprise 2.0”, Sand Hill Group.

Shahin, A. (2008), "Design for Six Sigma (DFSS): lessons learned from world-class companies", International Iournal of Six Sigma and Competitive Advantage, Vol. 4 No. 1, pp. 48-59.

Watson, G.H. and Deyong, C.F. (2010), "Design for Six Sigma: caveat emptor", International Iournal of Lean Six Sigma, Vol. 1 No. 1, pp. 66-84.

Wijaya, S., Spruit, M., Scheper, W. and Versendaal, J. (2011), "Web 2.0-based webstrategies for three different types of organizations", Computers in Human Behavior, Vol. 27, pp. 1399-1407.

Yang, K. (2005), Design for Six Sigma for Service, McGraw-Hill Education, Department of Industrial and Manufacturing Engineering, Wayne State University, Detroit, Michigan.

\section{Corresponding author}

Dora sousa Magalhaes can be contacted at: dorasousamagalhaes@gmail.com

For instructions on how to order reprints of this article, please visit our website:

www.emeraldgrouppublishing.com/licensing/reprints.htm

Or contact us for further details: permissions@emeraldinsight.com 